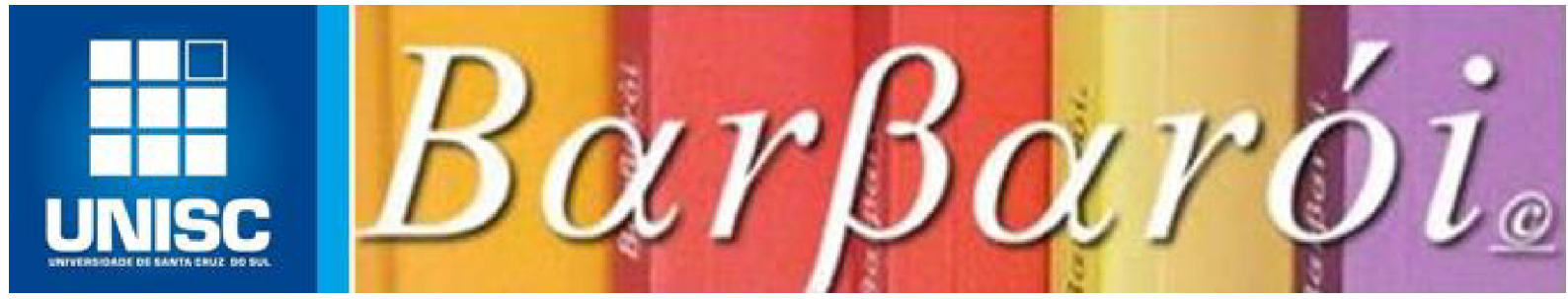

\title{
OS DESAFIOS NA CONSTRUÇÃO DE UMA UNIVERSIDADE COMUNITÁRIA: UM OLHAR A PARTIR DA CONDIÇÃO DE REITORA. \\ DOI: http://dx.doi.org/10.17058/barbaroi.v0i59.16982
}

\author{
Carmen Lúcia de Lima Helfer \\ Entrevistada - Universidade de Santa Cruz do Sul - UNISC - Brasil \\ César Hamilton Brito de Goes \\ Entrevistador - Universidade de Santa Cruz do Sul - UNISC - Brasil \\ Marco André Cadoná \\ Entrevistador - Universidade de Santa Cruz do Sul - UNISC - Brasil
}

\section{Resumo:}

A entrevista aborda temas relacionados ao processo histórico de construção de uma Universidade Comunitária, em especial da Universidade de Santa Cruz do Sul (UNISC). A partir de relatos acerca de sua experiência profissional, enquanto professora e gestora na UNISC, a professora Carmen Lúcia de Lima Helfer analisa os diferentes momentos, os diferentes desafios, as dificuldades e as conquistas no trabalho coletivo de construção de uma experiência de Universidade Comunitária no Rio Grande do Sul. A entrevista aborda, também, os caminhos e os descaminhos do ensino superior no Brasil, em especial no último período, quando as mudanças das políticas públicas e direcionadas ao ensino superior no País desafiaram os gestores universitários a mudanças tanto no que diz respeito à gestão administrativa quanto no que diz respeito aos projetos de Universidade que orientam as ações de ensino, de pesquisa e de extensão universitários. Relacionada a essa última temática e provocada pela própria proposta do número especial da Barbarói, a professora Carmen resgata a participação do Departamento de Ciências Humanas na UNISC e o lugar das ciências humanas na formação universitária.

\section{Palavras-chave:}

Universidade Comunitária, UNISC, Crise e Universidade, as ciências humanas na formação universitária.

\section{Entrevistadores:}

Professora Carmen. Primeiro, queremos agradecer muito sua disponibilidade de tempo e seu interesse em participar desse projeto da BARBARÓI. Esse é um projeto que nós, professores e professoras do agora extinto Departamento de Ciências Humanas, decidimos executar, com o

Barbarói, Santa Cruz do Sul, n.59 - número especial, p.<84-112>, Ago./Set. 2021 


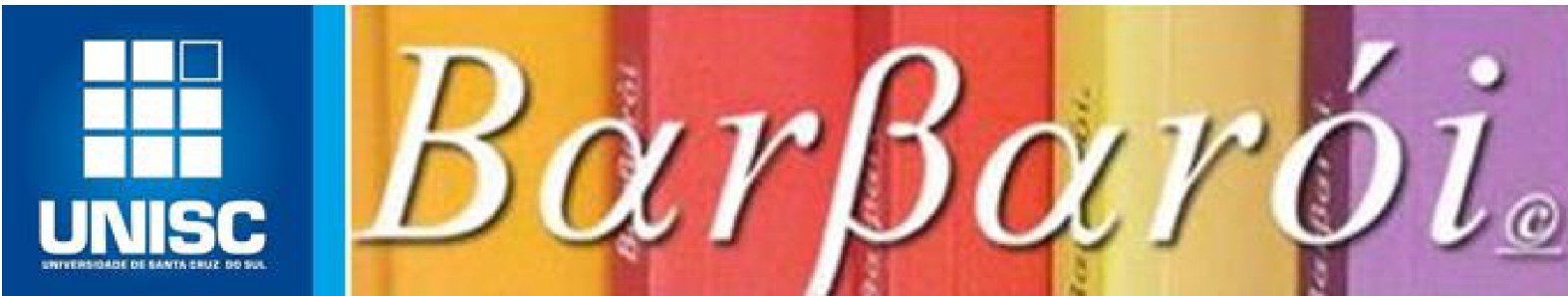

Mas eu tinha magistério no Ensino Médio e fiz concurso para trabalhar como professora estadual e logo fui nomeada. Isso em Candelária ainda. Comecei a dar aula no Colégio Guia Lopes. Daí o que aconteceu? Quando eu me formei em Direito, eu já era professora. E já era professora concursada. E sempre gostei de dar aula. Não era o que eu queria, na minha primeira ideia, mas foi onde eu comecei a minha trajetória profissional. E eu me formei em Direito, em 1982, mas nunca advoguei. Eu sou Bacharel em Direito, formada na turma de 1982, pela FISC.

Não foi uma decisão difícil optar pelo magistério. E não foi porque o Direito me dava uma formação que eu achava mais interessante e aberta do que a própria Pedagogia. Minha mãe, na época, fazia Pedagogia de manhã e eu vinha à noite cursar Direito. Eu fui uma aluna de ônibus diário, por isso também entendo essas dificuldades de muitos de nossos estudantes hoje. Eram estradas sem asfalto, era pedra, era chuva, era pó, era barro. Mas eu me achei na formação, que é uma formação geral cidadã, e fui uma boa aluna do Direito. Me formei, continuei professora, e em 1983 eu mudei para Santa Cruz do Sul. Desde então moro aqui em Santa Cruz do Sul. E eu, quando cheguei aqui, fui dar aula na Escola Ernesto Alves de Oliveira.

Eu era formada no magistério e, portanto, dava aula para as séries iniciais, do ensino fundamental. E daí o que aconteceu? Fiquei um ano na Escola Ernesto Alves e no final do ano eu fui convidada, tanto pela professora Helga quanto pela professora Mirian Burgos, para trabalhar na Escola Educar-se. Isso foi em 1983, no final daquele ano. Eu fiquei muito feliz com o convite, porque era uma escola nova, uma escola que estava propondo uma educação diferenciada, e eu fui convidada para dar aula nas séries iniciais. Então, em 1984 eu começo meu contrato com a APESC. Em março daquele ano eu tive minha carteira de trabalho assinada, como APESC e cedida pelo estado. Na Escola Educar-se tive uma experiência maravilhosa, porque tínhamos formação, e foi ali que eu comecei a conhecer a Universidade, comecei a conhecer as pessoas com as quais depois iria participar da própria criação da UNISC. Conhecer pessoas como, por exemplo, o João Pedro, o Caco, o Luiz Augusto, o Edgar, entre outros.

\section{Entrevistadores:}

O registro desses nomes é muito interessante. São relações longevas. Tem colegas que estão na UNISC há quarenta anos.

\section{Carmen Lúcia de Lima Helfer:}

Por isso que eu digo que é DNA, é visceral essa relação. Porque quando eu entro na Educar-se, cedida pelo estado, morando há um ano em Santa Cruz, essa experiência me faz entender melhor os professores que vieram de fora. Um ano em Santa Cruz e sou convidada pelo meu trabalho realizado no estado, pela qualidade do trabalho. E eu prontamente disse sim. Porque era uma coisa nova, uma visão de educação que eu acreditava, porque a minha formação no Medianeira foi bem tecnicista. E eu brigava o tempo inteiro com as professoras dizendo que aquilo não era dar aula. Não podia ser dar aula.

Barbarói, Santa Cruz do Sul, n.59 - número especial, p.<84-112>, Ago./Set. 2021 


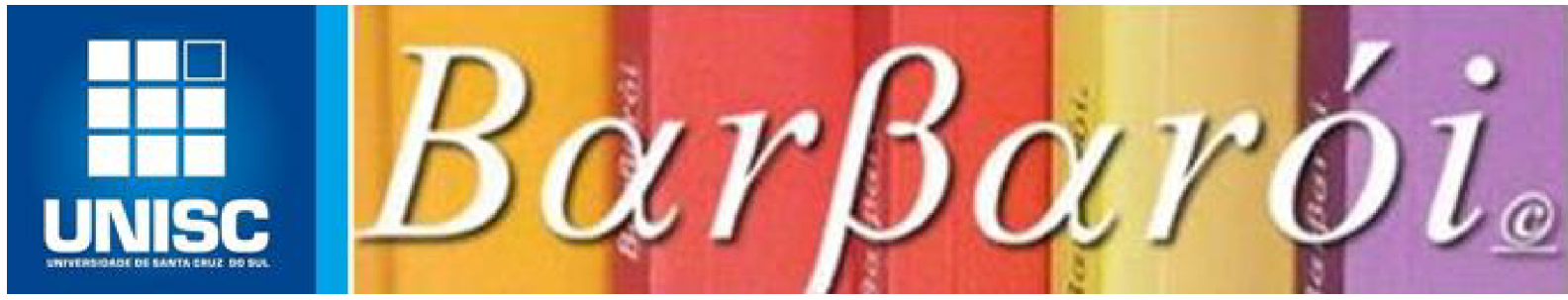

Pois é. Quem eram as pessoas naquela época. O professor Elenor, diretor da Escola Educar-se; a professora Helga, que era e é, até hoje, professora da UNISC (ela era da Faculdade de Filosofia, Ciências e Letras). Além deles, tinha a professora Derci, a professora Elisabeth, a professora Maria. E eu assisti, em 1980, o ato de transformação de Faculdades Isoladas para Faculdades Integradas, por ser aluna do Direito. Porque todos os alunos foram chamados e foram avisados que, a partir de então, nós seríamos Faculdades Integradas.

\section{Entrevistadores:}

Num momento em que o diretor das Faculdades já era o professor Wilson?

\section{Carmen Lúcia de Lima Helfer:}

Sim. O Wilson foi o primeiro diretor das Faculdades Integradas. Foi ele que anunciou, inclusive, no alto da escada (eu estava lá embaixo).

A Escola Educar-se começou com o diretor Elenor, a professora Helga, a professora Miria, os departamentos existentes na época davam uma assessoria aos professores. Nós iniciamos com o Jardim A, Jardim B, primeiro, segundo, terceiro e quarto anos, e o primeiro ano do Ensino Médio. Então, foi implantando-se gradativamente. Era um time, bota time. A Sandra Mayer, da Educação Física, e o ensino médio começou a contar com quem: com o professor Caco, com o professor João Pedro. Na área da História, também era meu colega, hoje não está, o Jorge Cunha, que hoje é professor da Federal de Santa Maria, e que foi diretor da escola.

Então, eram nomes que circulavam nas faculdades, na área das licenciaturas e no ensino básico, e que acabavam nos dando uma assessoria. Eu posso dizer, assim, tranquilamente: foram anos onde eu fiz a minha formação superior na prática. Porque a gente lia muito, estudava novos modelos pedagógicos, e tem que considerar que naquele momento aconteceu a abertura política no País, 1984, 1985. Então, vínhamos nós, jovens professoras, numa proposta do Educar-se, que era educar-se a si, com um propósito de desenvolver tanto o individual quanto o coletivo, num tempo de abertura política. Foi um tempo muito bom.

\section{Entrevistadores:}

Nessa época, a discussão sobre a criação de uma Universidade já estava presente ou vai acontecer mais tarde?

\section{Carmen Lúcia de Lima Helfer:}

$\mathrm{Na}$ verdade, desde 1986, sim, havia interesses e a gente ouvia esse desejo. Mas não participei diretamente. Só a partir de 1990, quando eu venho para cá, FISC. Então, entre 1984 e 1989, eu trabalhei como professora dos anos iniciais, e ali eu já me permiti pegar turmas da segunda, terceira e quarta séries. Eu nunca me contentei em ficar só com uma turma. Eu gostava de mudar. Nós tínhamos uma turma de professores cedidos, de primeira a quarta série, naquela época era quarta série, e foi implantando-se gradativamente a escola até chegar, no que ela é hoje, uma escola completa.

Barbarói, Santa Cruz do Sul, n.59 - número especial, p.<84-112>, Ago./Set. 2021 


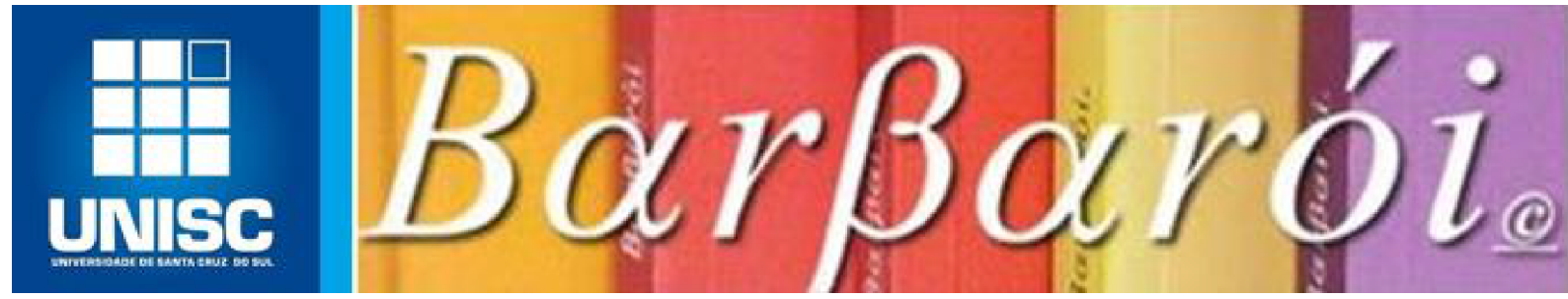

\section{Carmen Lúcia de Lima Helfer:}

Eu tenho quase certeza que o Luiz Augusto me convidou por causa disso. Porque eu estava me relacionando com as Secretarias Municipais de Educação.

Mas voltando, sobre as evidências de um movimento já consciente de construção da Universidade. Tinha outra evidência. Nós precisávamos ter pesquisa, ensino e extensão. Então, nós fomos, primeiro, uma instituição de ensino. Em seguida a extensão foi crescendo na medida em que foi avançando o projeto de Universidade. E, em 1992, eu fui convidada para ser assessora. Lembram da Mariza Christoff? Ela foi a primeira assessora de extensão. Aí eu fui trabalhar na Pró-Reitoria, com, 20 horas, porque nas outras 20 horas tinha a Coordenação do Programa de Docentes Leigos. Então, a Marisa já estava, aí eu entrei e, em seguida, veio a Susana Ramos.

$\mathrm{Na}$ época era assessora técnica. O Rogério era o coordenador de extensão e o Luiz Augusto já era Superintendente de Pesquisa e Extensão, junto com o Wilson, que era Diretor da FISC. Era no bloco 06, perto da sala do Wilson. Eu trabalhava à tarde, o Rogério era o Coordenador de Extensão, o Sílvio era Coordenador de Pesquisa, e o Luiz Augusto era o Superintendente.

Depois o Rogério foi para o seu mestrado, em Florianópolis, em 1994. Aí o Luiz Augusto me convidou para ser a coordenadora de extensão. Em 1994 eu fiquei todo o ano no lugar do Rogério. Então, a Susana e a Mariza trabalhavam com a extensão, o Silvio trabalhava com a pesquisa e eu fiquei um ano na coordenação de extensão. E foi muito legal, assim, porque houve uma expansão muito grande dessa relação com as escolas e com os departamentos ligados às licenciaturas e humanidades.

\section{Entrevistadores:}

Certamente, naquele periodo os desafios da extensão já eram grandes, pois, além daqueles já colocados no campo da educação havia outros departamentos, outras áreas do conhecimento.

\section{Carmen Lúcia de Lima Helfer:}

Sim. Os próprios departamentos começaram a ampliar as relações com as escolas. Havia uma grande relação do Centro de Ciências com as escolas. E havia todo um projeto para um programa de educação científica. Vocês lembram das feiras de ciências? Havia também a formação de professores para lecionar Ciências Naturais, Química, Física, Matemática. Eu fiz muitos cursos desses. Porque o bom de ser professora da Educar-se é que participava de todas as atividades formativas. E foram anos de muita intensidade do conhecimento na FISC. Era um momento importante, de abertura política, discussão de rumos diferenciados para a educação, e foram muitos eventos importantes, porque ao mesmo tempo capacitava para uma abertura das cabeças também. Muitos professores de fora vinham para cá. Nós tínhamos os professores, todos da especialização, de Santa Maria. Excelentes professores da UFSM. Então, pulsava muito estudo e eventos aqui. A professora Virgínia já era do departamento de Ciências Humanas, professor Luiz Augusto, professor Caco, professor João Pedro. Havia um embrião que depois participaria da formação dos novos departamentos.

Barbarói, Santa Cruz do Sul, n.59 - número especial, p.<84-112>, Ago./Set. 2021 


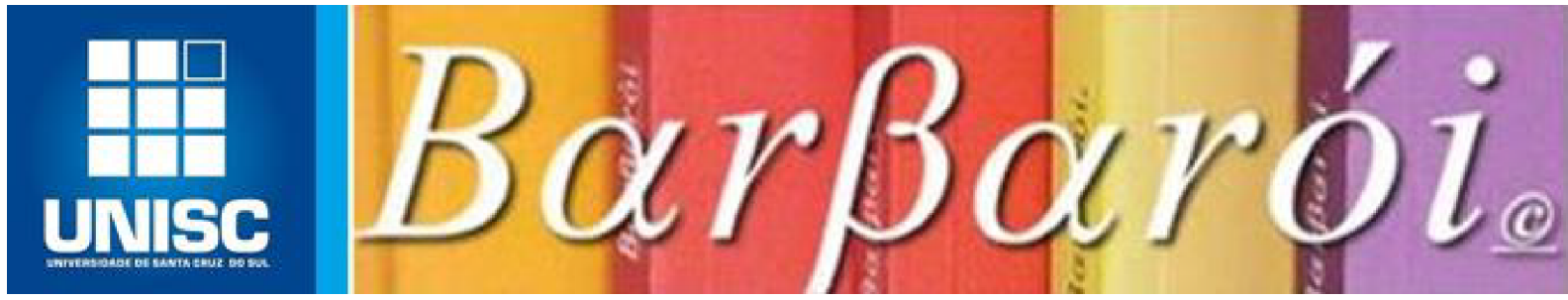

\section{Entrevistadores:}

O que é importante, pois estamos falando dos meios através dos quais os grupos se formam, de como determinadas equipes vão se constituindo e criando condições para acontecimentos posteriores.

\section{Carmen Lúcia de Lima Helfer:}

Sim. O que acontece é que os departamentos sempre foram os núcleos de professores. Então, para eu buscar um professor de Português, falava com o chefe de departamento. Se não tinha professor dos departamentos, eles indicavam os melhores professores da rede básica ou os recém-formados, muito bons. Professores excelentes. Muitos professores que ainda hoje estão na UNISC começaram lá. Então, os departamentos sempre foram os núcleos que informava quem iria dar aula. Sempre houve essa ligação. E eu sempre respeitei. Nunca tive autonomia para indicar professores.

E tinha algo que para mim sempre foi muito importante. Era um princípio. Os departamentos eram as menores frações da administração básica. Se havia uma relação com os departamentos, com as licenciaturas, então era ali, também, que havia a formação de quem poderia ser indicado para dar aula nesses cursos. E também fazia extensão logo em seguida. Ocorreu uma relação forte. A minha começa por esse Programa dentro do Departamento de Educação.

\section{Entrevistadores:}

Vamos aproveitar esse gancho porque agora a gente entra em um outro campo. Você vem, então, para a extensão, para a assessoria de extensão, assume durante um ano, é um momento de expansão das atividades na educação, inicia sua atuação como professora nas Faculdades, entra na gestão da Universidade. Que mudanças qualitativas ocorrem nesse processo, nesses diferentes momentos?

\section{Carmen Lúcia de Lima Helfer:}

Em 1994 muda, é um marco. O Prof. Luiz Augusto me convida para ficar no lugar do Rogério, eu já estava na Pró-Reitoria, já conhecia o trabalho e fiquei por um ano. Em 1993, quando eu já estava na Assessoria, Rogério e eu criamos o Programa Terceira Idade. Então, naquele momento a relação com a comunidade estava se intensificando. É um momento no qual foi criado o Conselho da Mulher, com a professora Lélia, com sindicalistas e com professores da UNISC. Nós fazíamos sessões de cinema, nos sábados à tarde, com as mulheres sindicalistas, o que resultou na criação do Conselho da Mulher. O Programa Terceira Idade levou à criação do Conselho do Idoso. Em 1994 havia uma relação muito forte com o Conselho de Crianças e de Adolescentes e com os Conselheiros Tutelares. Nós tínhamos um programa, também, para a infância. Então, vejam que começa a crescer os segmentos na área social, para além das escolas. E isso tudo na Gestão do Professor Luiz Augusto, que era o Pró-Reitor de Pesquisa e Extensão. O Rogério foi para o mestrado, em 1994 e em 1995 vou

Barbarói, Santa Cruz do Sul, n.59 - número especial, p.<84-112>, Ago./Set. 2021 


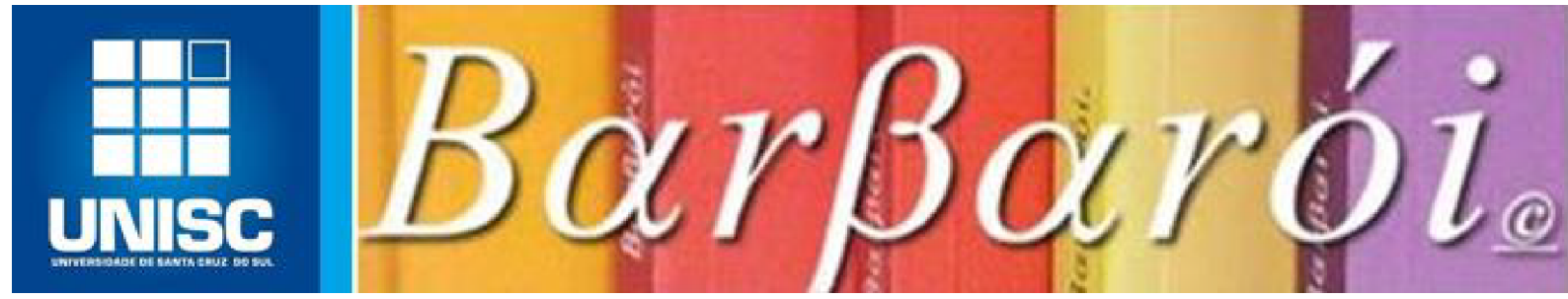

ligada a isso. Depois a UNISC foi uma universidade onde a extensão começou a crescer e cresceu forte. Eu acho que isso marcou muito a minha vida. Saio para o mestrado, estudo dois anos na PUC, no meu terceiro ano, então, fazendo a minha dissertação, eu acabo escolhendo o tema extensão.

Em 1997 veio a professora Eunice Gai, para coordenar a Extensão e eu ainda envolvida com a minha dissertação e a Paula também tinha saído para o mestrado. Nós tínhamos um compromisso institucional de fazer mestrado. Então, só ficaria na UNISC se eu fizesse mestrado, com o título de Mestre. Era um compromisso e, inclusive, com tempo para terminar: 1997. Isso numa condição em que eu dava aula para cumprir as horas. Voltei para o departamento, na época estava com as horas dispensadas para pesquisa e dissertação. Estava dando aula, me lembro como se fosse hoje, numa daquelas salas do Bloco 3, entra o Luiz Augusto e me convida para voltar para a coordenação de extensão. Eu, na hora, disse sim.

Isso em 1997, ele me convida para ocupar, então, o cargo de Coordenadora de Extensão. Ah, me criticaram no departamento, "porque tu tens que fazer a tua dissertação, porque tu vais te atrasar, porque não sei o que". Mas só que eu achei uma oportunidade ímpar, eu estudando sobre extensão, fazendo um trabalho com os professores e poder praticar tudo aquilo. Eu achava que essa coerência só iria qualificar meu trabalho. Mal sabia eu que naquele semestre a Universidade assinou um convênio, via COMUNG, que aí já estava o COMUNG em ação, para fazer os cursos de educação profissional. Cursos vinculados ao Fundo de Amparo aos Trabalhadores. Mal eu sabia o tamanho daquilo. Porque nós tínhamos que organizar cursos de qualificação básica para toda a região. E nesse meio tempo, já funcionava nesse prédio 25 a extensão, junto com o Prof. Luiz Augusto. Aí eu acabei coordenando todo o FAT. Foi uma trabalheira, às vezes a gente saía daqui às três da manhã. Uma noite eu passei acordada fazendo os horários dos mais de cento e tantos cursos naquela época. Para tudo que era lugar, do Alto Taquari, do Vale do Rio Pardo, eram cursos curtos de qualificação profissional, mas tínhamos que organizar. Os participantes ganhavam material, ganhavam alimentação, tínhamos que organizar docentes. Eu quase me vi louca. A sorte é que Susaninha e Mariza eram parceiras. Eu sinto saudade até hoje, porque nós construímos laços fortes, vínculos fortes.

\section{Entrevistadores:}

É possivel estabelecer alguma relação desse trabalho de formação profissional com a criação do CEPRU?

\section{Carmen Lúcia de Lima Helfer:}

Tenho certeza absoluta. Foi o embrião da criação do CEPRU. Nada é por acaso. O FAT acabou fazendo com que a UNISC se relacionasse com o mundo do trabalho, com a educação profissional básica, com várias demandas da comunidade. Havia uma crítica na época: que nós estávamos muito envolvidos com as demandas. Imagina, ir para a comunidade, a comunidade vinha a mil para cima da Universidade. E não responder a comunidade era a Universidade perder uma oportunidade de ter esses municípios com a gente. Aí nós

Barbarói, Santa Cruz do Sul, n.59 - número especial, p.<84-112>, Ago./Set. 2021 


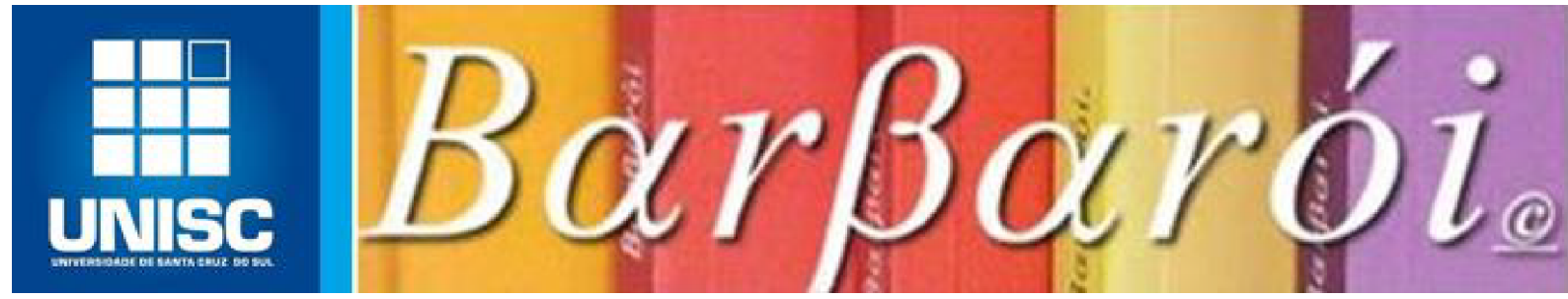

comunitária. Era um povo altamente comprometido com esse ideal. Então, nós fazíamos de tudo para dar certo. E nesse tempo, o que é que se fez: as superintendências viraram Pró-Reitorias. Então, era o reitor, professor Wilson, e o vice era o Professor Luiz Augusto. Já 1993/2, vem o curso de Psicologia, de Informática, e de Enfermagem. Começa a expansão da Universidade. E aí eu até me emociono porque a gente acompanhou tudo isso. Com o professor Luiz Augusto, Pró-Reitor, começa a preocupação com o desenvolvimento da pesquisa. E em 1994 nasce o $1^{\circ}$ mestrado em Desenvolvimento Regional, um programa interdisciplinar, que foi o primeiro no Brasil. E a luta para implantar, porque era algo novo, como também desconhecimento da CAPES, deste tipo de Mestrado.

Esse programa foi o primeiro na área. Em 1994, ocorreu a implantação. E eu continuei trabalhando na coordenação de extensão. Aí o professor Wilson assumiu a Pró-Reitoria de Pesquisa e Extensão em 1998, e eu continuo trabalhando como coordenadora de extensão. E tudo crescendo, pois já tinha cursos de qualificação profissional, já tinha um Programa de Terceira Idade consolidado, começam programas de pós-graduação na Universidade, Programa Universidades-Empresas, Redes de Cooperação, todos financiados pelo Governo do Estado.

\section{Entrevistadores:}

Aproveitar sua fala para perguntar sobre a importância do professor Wilson na sua trajetória: que influência o professor Wilson teve?

\section{Carmen Lúcia de Lima Helfer:}

Sim. O professor Wilson, era muito determinado. Ele tinha uma certeza, queria tornar a UNISC uma grande Universidade. E arrojado, porque decidia "vamos criar curso x, vamos criar curso y". E houve uma grande expansão no período entre 1994 e 1998, eu diria até os anos 2000. Éramos um parque de obras, isso é verdadeiro. Foi financiamento do BNDES, que ajudou a expansão de cursos na Área da Saúde, Arquitetura e Engenharia. Foi pulsando uma grande expansão. Voltei, em 1997, já tinha Engenharia Agrícola, já estava em estudo a Engenharia de Produção, já tínhamos a Fisioterapia, Nutrição, Arquitetura. A UNISC foi só crescendo. Muito rápido.

Então, a influência, é que ele sempre era favorável à expansão. E como era bom, tinha dinheiro. Eu também vivi outras fases, que não a que nós estamos vivendo hoje que talvez seja a pior, mas também ocorreram fases difíceis. Então, o Wilson vira Pró-Reitor, continua a expansão dos mestrados, ele tinha muito foco nisso, foi criada a Coordenação de Pós-Graduação Lato Sensu, que a professora Liane M. Kipper assumiu. Tinha a professora Eunice Piazza Gai, da Pós Stricto Sensu, tinha o professor Rogério, da Pesquisa, e eu coordenava a Extensão. Era essa a configuração da Pró-Reitoria, com o Wilson também. E o Luiz Augusto como Reitor. Nos anos 2000, as licenciaturas, que tiveram grande impulso nos Cursos de Férias, já começam a dar sinais da diminuição. Começa uma expansão da área da saúde e das engenharias, a área dos mestrados, doutorados. Então, eu qualifico como uma grande expansão da UNISC do período entre 1993 e 2005, quando entra a primeira crise das

Barbarói, Santa Cruz do Sul, n.59 - número especial, p.<84-112>, Ago./Set. 2021 


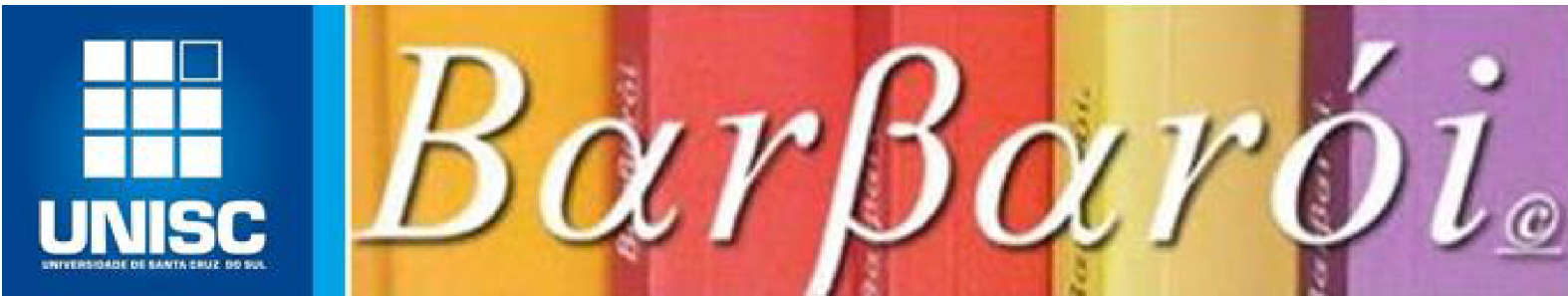

privadas e do EAD. Então, a extensão cresce nos vários segmentos, de tal modo que é pensada uma estrutura própria da extensão. Em 2002, então, foi criada a Pró-Reitoria de Extensão e Relações Comunitárias, da qual eu fui a primeira Pró-Reitora.

\section{Entrevistadores:}

Vamos considerar esse momento de posse como Pró-Reitora de Extensão. As informações da estrutura do COMUNG, da ideia de luta pelo ensino superior comunitário, essas ideias já estavam presentes em sua trajetória, em seus modos de pensar a própria Universidade?

\section{Carmen Lúcia de Lima Helfer:}

Quando o Wilson era Reitor, eu já participava no COMUNG. Porque o COMUNG foi criado em 1996, e o Wilson participava como Reitor. Tenho que deixar claro, a UNISC sempre participou desses movimentos, das lutas coletivas. O Wilson, depois o Luiz Augusto também foi presidente do COMUNG. O FAT foi oriundo do COMUNG. Nessa época, foi criado o Programa de Integração da Universidade com a Educação Básica, o PIEB. Lembram? Que até pouco tempo atrás ainda existia. Eram as quinze instituições do COMUNG, participando de formação de professores e de serviços de extensão na comunidade escolar. Ali houve ações coletivas do COMUNG, teve produção coletiva, nós tivemos, por muito tempo, coordenação disso. Eu fui à primeira reunião do PIEB, que foi lá em Pelotas. Eu era uma criança perto daquelas professoras bem mais velhas. Eu pensei, cá comigo, "o que é que eu estou fazendo aqui"? Mas a nossa Universidade era muito jovem em tudo. Nós tínhamos que nos mostrar presentes. Mas, ao mesmo tempo, tínhamos que conquistar a importância de Universidade, isso não era tão fácil para as mais antigas, que se sentiam meio donas. Também tínhamos que conquistar um lugar, de competência, de reconhecimento, e eu acho que a UNISC fez muito bem isso ao longo da trajetória com os seus reitores. Todos, todos contribuíram.

Retomando, minha passagem pela Pró-Reitoria de Extensão, em 2002. Ali houve uma expansão muito forte e, ao mesmo tempo, uma autonomia maior para a extensão. E eu convidei a Prof ${ }^{a}$. Paula para ser a Coordenadora de Extensão. Vocês estão presenciando que está transitando na minha fala a importância das Humanidades. O reitor era das Ciências Humanas, a coordenadora das Humanas, eu era do Departamento de Educação. As ciências humanas sempre tiveram um lugar de destaque na trajetória histórica desta Universidade. Depois veio o Caco, como Pró-Reitor de Planejamento; nesse período do Reitor Luiz Augusto, foi criada a Pró-Reitoria de Planejamento e Desenvolvimento Institucional, em que depois o João Pedro foi o Pró-Reitor.

E, em 2005, termina o mandato do professor Luiz Augusto. E se iniciam as gestões do professor Thomé, entre 2006 e 2013. Em 2005 me preparei para sair da Reitoria, eu achei que ia sair, não estava esperando um convite para ir para a Pró-Reitoria de Graduação.

E aí eu digo que é um marco na minha vida. É um marco porque, eu digo para todos, quem passa por ali pode ser Reitor. Porque é uma Pró-Reitoria pesada, é uma Pró-Reitoria em que também peguei a expansão dos cursos, a avaliação de cursos, trabalhei muito na avaliação de reconhecimento e renovação de reconhecimento dos cursos, para que a UNISC ficasse com

Barbarói, Santa Cruz do Sul, n.59 - número especial, p.<84-112>, Ago./Set. 2021 


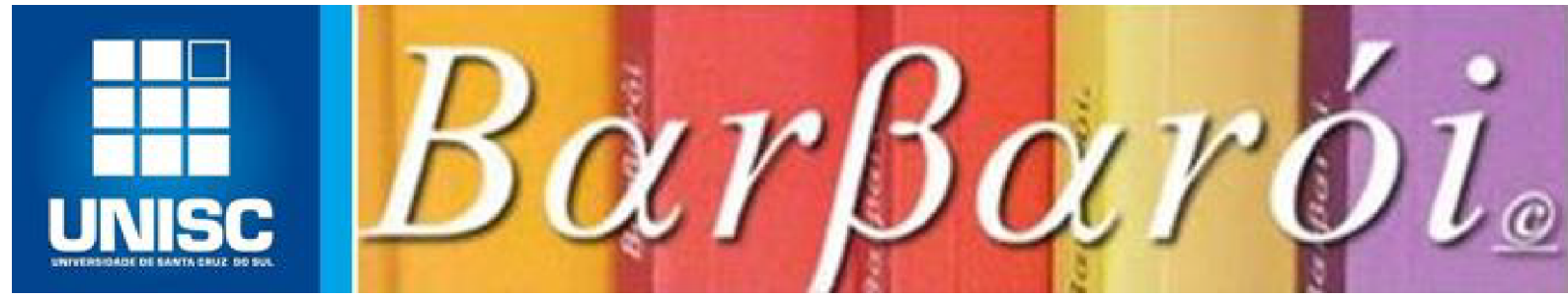

contextos que, muitas vezes, os cursos pretendem e necessitam de maior autonomia para organizarem suas próprias politicas curriculares, pedagógicas?

\section{Carmen Lúcia de Lima Helfer:}

A expansão ocorreu principalmente na área da saúde e na área das engenharias. Tivemos a criação dos cursos de Serviço Social, Filosofia e Ciências Sociais. Em 2006, é implantado o curso de Medicina. E isso fez uma diferença fantástica. Foi uma conquista da gestão do professor Luiz Augusto, embora a implantação foi na gestão do professor Thomé, comigo na graduação. Ele já foi construído com um projeto pedagógico diferenciado. E nós tínhamos que criar, sim, uma política de graduação. E, naquela época, nós fizemos um grande trabalho, de coleta de dados de todas as áreas do conhecimento, no sentido dessa construção. Foi feito um grande diagnóstico da graduação. Quem éramos, o que tínhamos e para onde íamos. Desse diagnóstico, que envolveu todos, o César participava da comissão, ele há de lembrar, nós criamos dez políticas que são até hoje as políticas que existem.

Envolvemos a comunidade interna nesse diagnóstico. Tínhamos clara a direção, para onde crescer e como. A partir daquilo, nós tínhamos mais delineado o caminho a percorrer. E o que aconteceu? Nós tínhamos reuniões por áreas, onde conversávamos. Já se mostravam cursos que tinham muitos alunos e cursos que tinham menos alunos. E iniciou uma grande queda nas licenciaturas. E isso foi o primeiro marco da minha vida, no sentido de criar um currículo integrado entre as licenciaturas para dar conta da oferta. E nós mantivemos, até hoje, dez licenciaturas. Nessa época, os cursos de Filosofia e de Ciências Sociais caíram muito na demanda, na procura. Concluímos o curso de Filosofia e não ofertamos mais, porque não havia interessados. E já começavam a se delinear sinais da necessidade de sustentabilidade institucional, que não podia se perder. E aí se estabelecem parâmetros de oferta: menos de 20 alunos não poderia ter oferta de vestibular. Porém, o que aconteceu? Com esse primeiro estudo de integração e flexibilização das licenciaturas, nós demos uma vida, um sopro, porque até agora elas estão sobrevivendo. Mas nem tudo deu certo nessa integração.

\section{Entrevistadores:}

Mas, naquele momento, havia uma avaliação de que a Comissão que foi criada poderia ter avançado muito mais do que avançou na discussão da integração de um projeto de graduação. Isso aconteceu?

\section{Carmen Lúcia de Lima Helfer:}

Aconteceu. Foi um ano de muita discussão, e aí começa, e acho que não precisamos ter filtros, começamos a ter delineamentos, delinear-se uma disputa de áreas, começam a se constituir, assim, as áreas específicas sobre as áreas humanas. E eu lembro que nós não tínhamos um percentual, por prática política de gestão, nós não deixávamos fechar disciplinas das humanidades. Mas já havia sinais fortes dessa questão, porque começou a ampliar os departamentos, ampliar o número de cursos, o número de alunos vai para 11.600, em 2013/2014. E o que se começa a se ver? Que, de fato, começa a disputa e a defesa dos seus nichos de conhecimento. Não tem como não dizer isso. Foi e ainda tem. Nós já constituímos,

Barbarói, Santa Cruz do Sul, n.59 - número especial, p.<84-112>, Ago./Set. 2021 


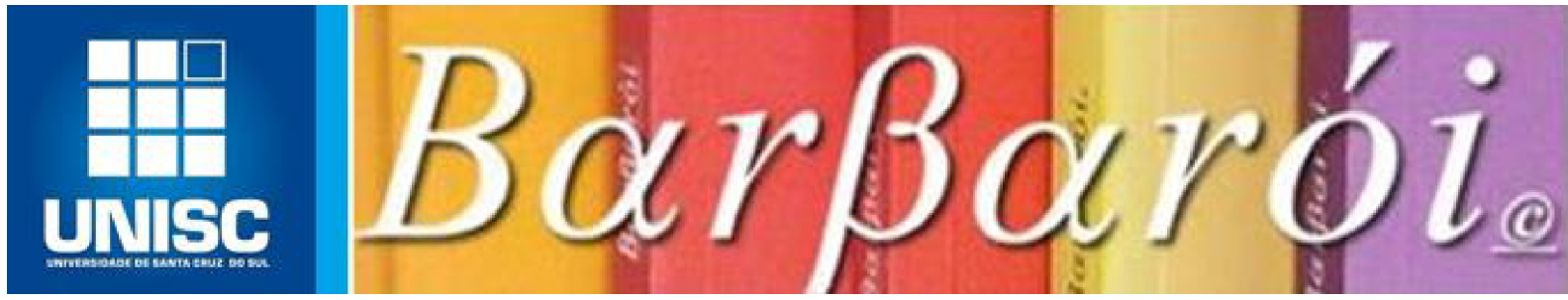

\section{Entrevistadores:}

Nós queremos saber dessa experiência. A primeira mulher que é Reitora na UNISC. Mas, também, a partir de seu relato, num momento em que, pessoalmente, já tinha muito acúmulo enquanto gestora da Universidade. Saber como esse "projeto", inclusive pessoal, foi sendo construído, como ele se efetivou e o que ele representa, sem dúvidas são questões da maior importância.

\section{Carmen Lúcia de Lima Helfer:}

Eu acho que vocês vão ter que marcar outro dia. Mas eu confesso que nunca tinha posto na minha vida isso: ser Reitora. Isso não foi um objetivo na minha vida. Meu objetivo sempre foi trabalhar bem e trabalhar pela UNISC e na UNISC. Vestir a camiseta com comprometimento. Sempre foi esse. Agora, quando isso mudou? Mudou quando, de fato, pessoas começaram a defender esse projeto. Eu não estou aqui por mim, eu estou aqui porque houve confiança de muitas pessoas, no meu trabalho, em mim. E foi o que me fez pensar, em 2013, "bom, quem sabe?". Eu começo a alimentar essa ideia, mas não veio de mim. Ela veio de fora para dentro de mim.

E vocês colocam bem. O que me fez pensar que eu poderia ser Reitora? Exatamente uma trajetória de construção e de aprendizagem, com os três Reitores. Porque eu sempre me coloquei a serviço deles. Tanto que quem aparecia eram eles, não eu. Eu era sempre uma pessoa do grupo que trabalhava para as coisas darem certo para a UNISC. Então, essa trajetória de construção, como se diz, de conhecer a UNISC, seu funcionamento, me levou a pensar que eu poderia aceitar o desafio de ser Reitora.

E olha que, em 2013, nós estávamos no auge do FIES, tinha uma receita, um superávit na Universidade. Se os outros Reitores passaram por crises, o Prof. Luiz Augusto passou, o Thomé passou, mas o Prof. Thomé terminou num momento muito bom da Universidade. E eu peguei esse momento, tanto que ter três chapas é um indicativo de que a situação estava boa. Mas por que eu penso assim "olha, eu trabalhei tanto para chegar aqui e, principalmente pela graduação, por que não?”. Aceitei.

Mas eu me preparei para a eleição. Quem estava comigo sabia que eu me preparei para ganhar ou para perder. E aí o que aconteceu que eu não estava esperando que acontecesse: mudanças drásticas na política da educação superior a partir de 2015. Foi aquela coisa assim "e agora? Sou eu que estou aqui, a UNISC precisa continuar". E foi muito sério o ano de 2015, quando o FIES, na calada da noite, de dezembro para janeiro, mudou. Eu durmo com um programa e acordo com outro. E a UNISC, com 52\% de alunos com financiamento. Eu pensei cá comigo, “e agora o que nós vamos fazer"? Foi o pior ano para mim, porque o FIES começou a atrasar, nós tínhamos que ir ao banco buscar recursos para pagar a folha, ninguém perguntava quem pagava o juro. O superávit que nós tínhamos começou a diminuir com a redução do programa e da receita. Consequentemente, 2016 nós não sentimos muito, mas em 2017 a crise bateu forte e a diminuição de alunos na UNISC começa a ficar muito grande. E aí vocês sabem

Barbarói, Santa Cruz do Sul, n.59 - número especial, p.<84-112>, Ago./Set. 2021 


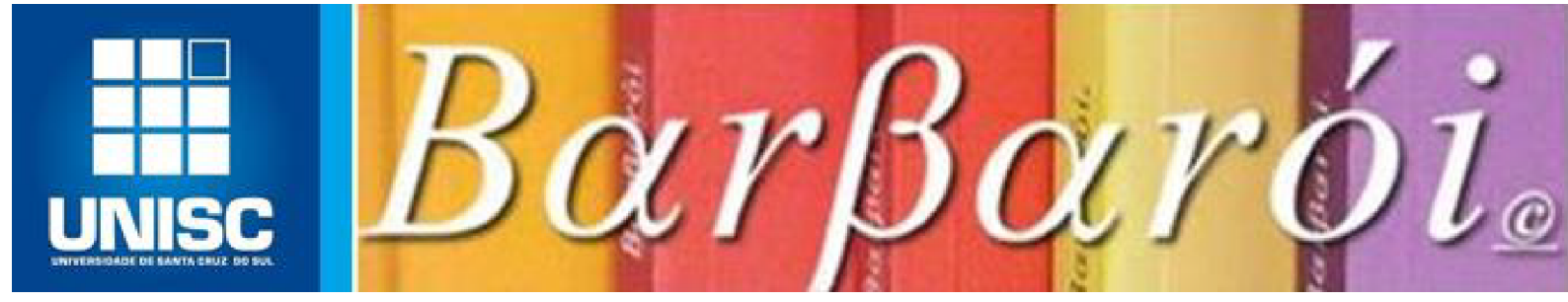

de crédito educativo, antes do FIES. Tínhamos bolsa de ensino, pesquisa e extensão, bem antes de bolsas PROUNI. Nós entramos no PARFOR, no PIBID, na Residência Pedagógica. Por quê? Porque iríamos manter as licenciaturas, como um compromisso histórico das nossas instituições comunitárias. Nós, e eu digo nós porque é uma luta coletiva, o que nós estamos passando agora é um momento difícil para todas as ICES. A concorrência, justamente por uma abertura das políticas de educação superior, começa a nos afetar de uma forma muito forte. Penso que o mercado vai regular o $\mathrm{EaD}$. Mas, enquanto não estiver regulado, nós vamos ser afetados, porque o país empobreceu, o Rio Grande do Sul mais ainda. Infelizmente, o Brasil não tem uma cultura de valorização da educação.

Por exemplo, não foi dito aqui que a UNISC foi a primeira a implantar o PROUNI, na gestão do professor Luiz Augusto. Nós fomos piloto para o PROUNI. E o PROUNI é um programa belíssimo de inclusão e de acesso de jovens que não estudariam nas nossas instituições. E nós temos PROUNI na UNISC, em todos os cursos. Então, tirar a filantropia e voltar a pagar impostos significa, para o COMUNG, vinte e sete mil estudantes que não estudariam mais com bolsas. Vocês sabem o que é isso? Em cento e sessenta mil estudantes. Parece pouco, mas vinte e sete mil não estudariam se não tivesse a bolsa do Programa. FIES é uma luta diária, porque, sem financiamento, não haverá acesso ao ensino superior. Além de valorizar pouco a educação e o estudo, o jovem brasileiro não tem condições de pagar uma Universidade privada ou comunitária. Então, daí vem todos os movimentos institucionais de hoje, para sobreviver nesse meio.

\section{Entrevistadores:}

Vamos ser diretos na pergunta, considerando sua reflexão sobre as dificuldades que as Universidades Comunitárias estão enfrentando nesse último periodo: as Universidades Comunitárias, e aqui a pergunta se dirige também para a UNISC, estão assumindo um desenho de Universidades privadas? É uma pergunta "bruta", mas releve esse imediatismo e considere que ela tem uma outra questão implícita: qual é o nosso horizonte enquanto Universidade Comunitária? No que nos distinguiremos? Diante dessa crise e de um contexto que está impondo respostas acerca de modelos de Universidade.

\section{Carmen Lúcia de Lima Helfer:}

$\mathrm{Na}$ letra da Lei temos as Universidades Públicas e Privadas. Nestas, com as instituições de ensino superior com fins lucrativos e sem fins lucrativos. As universidades comunitárias não têm fins lucrativos e seu modelo de sustentabilidade financeira está afetado pela concorrência da $\mathrm{EaD}$, com mensalidades muito acessíveis e pela queda de alunos pela crise social, econômica e financeira. Mas não quer dizer que assumirão o modelo de universidade particular. Temos que fazer sérios ajustes financeiros, mas não deixamos de manter nosso compromisso social e de qualidade do ensino, da pesquisa e da extensão. A força das ICES está na sua forte relação com a comunidade através da produção e da polarização do conhecimento, socialmente relevante. Precisamos manter e fortalecer a pertinência social e acompanhar as mudanças do mundo, da vida e do trabalho e reinventar nosso modelo.

Barbarói, Santa Cruz do Sul, n.59 - número especial, p.<84-112>, Ago./Set. 2021 


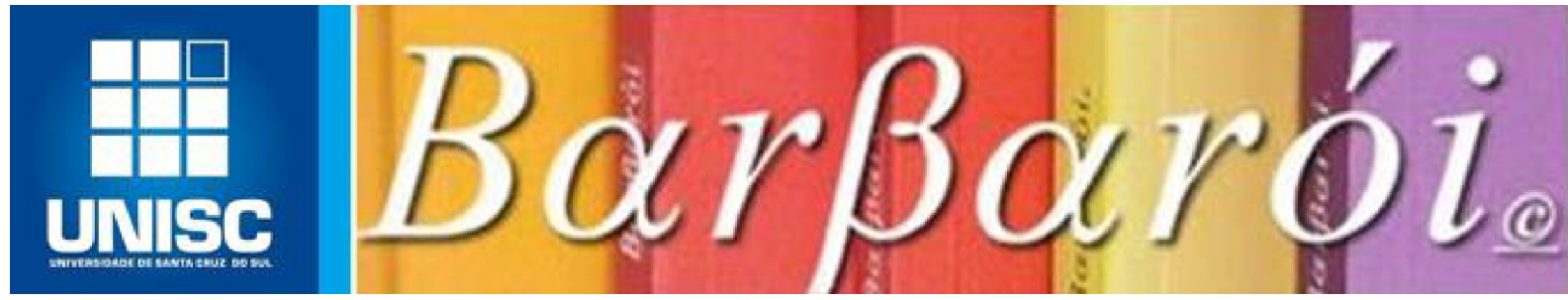

\section{Entrevistadores:}

Gostaríamos de conversar um pouco mais sobre a formação humanística na Universidade. Nessas alturas, você já nos colocou questões importantes, considerando a trajetória da própria UNISC nessa temática. Por exemplo, você nos colocou que a preocupação com a formação humanística está presente mesmo nos projetos de formação de professores, tão caros no periodo, inclusive, de criação da UNISC. Também está presente na criação dos cursos de licenciaturas que, como sabemos, sempre representam desafios sob o ponto de vista da sustentabilidade financeira da Instituição. Mas é importante pensar, também, em outros contextos. Em especial quando pensamos a formação humanística em outras áreas de conhecimento. Isso é importante, inclusive, porque você esteve, por um periodo importante, na Pró-Reitoria de Graduação, um espaço que, certamente, está no centro da reflexão sobre a natureza da formação universitária.

Então, essa discussão, na UNISC, tem diferentes momentos, aos quais se soma agora o projeto de Reinvenção Pedagógica, em nossa avaliação o primeiro momento em que a Reitoria, a partir de uma concepção de formação universitária, deixa claro para todos os cursos: todos têm suas especificidades, mas todos terão uma parte dedicada à formação geral, que será constituída por componentes que definem uma direção assumida pela Universidade e não pelas partes dessa.

\section{Carmen Lúcia de Lima Helfer:}

Bem. Iniciamos aqui uma segunda parte de nossa conversa. Eu quero aproveitar, primeiro, para agradecer mais essa oportunidade e, também, dizer que foi muito bom para mim conversar com vocês, porque olhar para o passado num momento que nós estamos vivendo, para mim gerou uma produção bacana de reflexão.

A partir de 2006, quando o professor Thomé foi eleito, eu saí da Extensão, onde foi criada uma Pró-Reitoria, com políticas de extensão, e passei a assumir, então, a Pró-Reitoria de Graduação. E foi aí que nos demos conta que nós não tínhamos uma política de graduação. Nós tínhamos uma quantidade de cursos, porque a Universidade cresceu, se expandiu. Se antes as Sociais Aplicadas e as Humanas eram as áreas principais de oferta de cursos, com o credenciamento da UNISC como Universidade, cresceu a área da saúde e começou a ser implantada a área das engenharias. Também em função das diretrizes curriculares nacionais DCNs. O Ministério da Educação, por volta de 2004, 2005, extinguiu os parâmetros curriculares e criou as diretrizes. Minha leitura hoje, olhando para trás: nós transformamos as diretrizes em legislação. E, hoje, para mim, é muito claro que as DCNs são grandes parâmetros para a formação dos cursos.

$\mathrm{Na}$ época, eu saí de uma Pró-Reitoria em que tínhamos muita autonomia para legislar e passei para outra que era absolutamente legislada pelo Ministério da Educação. Foi um impacto grande e sempre a UNISC teve a preocupação de fazer tudo conforme preconizavam as políticas públicas e a legislação do ensino superior. Quando, em 2006, 2007, nós

Barbarói, Santa Cruz do Sul, n.59 - número especial, p.<84-112>, Ago./Set. 2021 


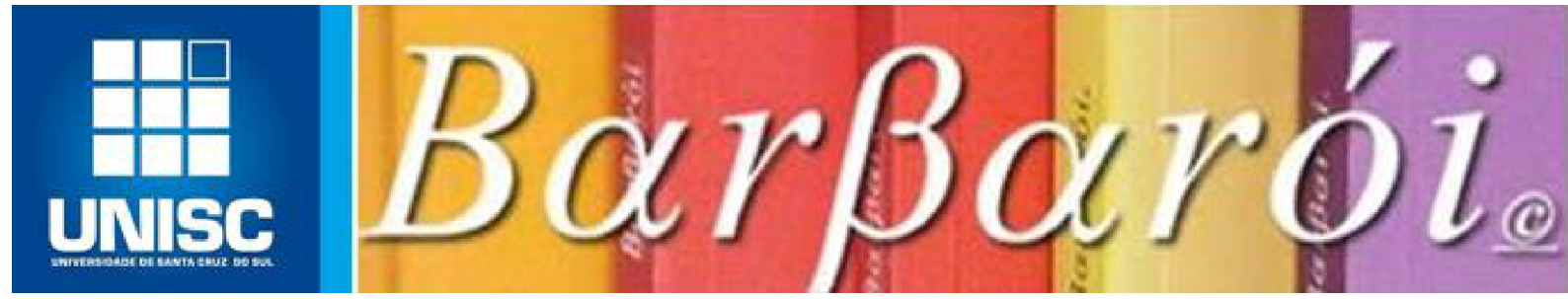

atravessamos uma crise, não tão difícil quanto a de hoje, mas atravessamos, onde nós tivemos pactos de redução de salários, de medidas lineares, nós entendemos que tínhamos que fazer algo. Na época, eu era Pró-Reitora, a Maria Salete Sartori era Coordenadora de Graduação e a Giana era a Coordenadora Pedagógica.

Nesse meio tempo, se implantou o curso de Medicina. Exatamente em 2006. E a Medicina nasce num outro formato de currículo. E aí começa uma revisão, ou, pelo menos, uma reflexão sobre modelos curriculares, mas não tínhamos nenhum documento que traçasse as políticas para a graduação da Universidade. Nós tínhamos as diretrizes externas, e as externas viraram legais. Eu penso que foi um tempo importante, mas que trouxe consequências para nós, porque, na verdade, a leitura que se tem hoje é que as diretrizes são os grandes parâmetros. Não são leis impostas. Não precisa engessar. Nós temos a liberdade que a gente não enxergava.

Em 2006, nós vimos que não tínhamos dados da graduação. Aí a Pró-Reitoria decidiu fazer um grande diagnóstico, envolvendo todos os cursos de graduação e, praticamente, todos os professores. Foi um trabalho que eu considero que foi um dos mais importantes que realizamos. Eu e a Giana capitaneamos todo esse trabalho, fizemos com base em instrumentos de pesquisa, construímos uma comissão, o César fazia parte, com professores de todas as áreas do conhecimento para nos assessorar. E construímos, então, o que nós chamamos de "o diagnóstico da graduação", trazendo elementos muito, muito ricos para a graduação da UNISC.

Em 2008, nós lançamos um livrinho azul, que vocês podem pegar, o Projeto Político-Institucional da UNISC. E nesse projeto estão as diretrizes políticas, que é o resultado do diagnóstico da graduação, que traz a história do diagnóstico $(2006,2007)$, as etapas e os pressupostos. E o que nós vimos? Que foi, de fato, um documento muito importante. Por quê? Porque nós trabalhamos conceitos orientadores para a construção das políticas.

Outras instituições fizeram também, porque isso aqui foi muito relatado como experiências da UNISC para outras instituições. Flexibilização curricular, mobilidade acadêmica. Esse material gerou as políticas e diretrizes de graduação. E o que nós tínhamos? Um diagnóstico que dizia "necessidade de formação pedagógica continuada". Foi apontado que tínhamos que ter uma política de qualificação. Esta foi uma primeira política que originou o NAP, Núcleo de Apoio Pedagógico. O que acontecia? Os professores que precisavam de orientação eram assessorados em termos de metodologias, de fundamentos da educação, de avaliação, de participação em eventos. Também, a necessidade da discussão e consolidação da formação por áreas, com o apontamento de disciplinas comuns por área. Isso foi em 2008 e nós estamos em 2020.

Então, aqui eu respondo que, de fato, nós começamos mudanças na graduação. Todas as políticas que hoje estão aqui, elas estão atualizadas. Só que, das políticas, entre a política e a ação, ficou um vácuo. O que nós fizemos, então? Foi um primeiro movimento, e naquela época havia um conflito grande, porque os cursos seguiam as diretrizes curriculares nacionais

Barbarói, Santa Cruz do Sul, n.59 - número especial, p.<84-112>, Ago./Set. 2021 


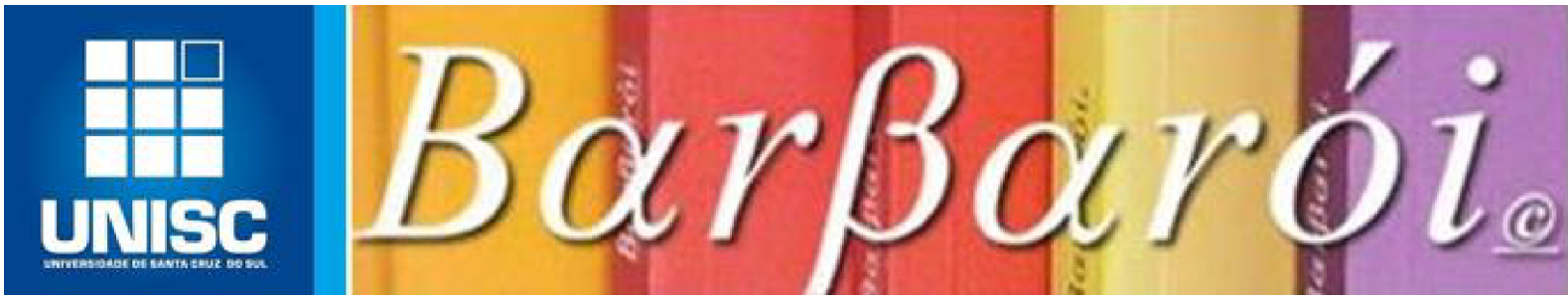

(DCNs). Os cursos não tinham, ainda, o NDE, Núcleo Docente Estruturante. Os colegiados acabavam formando um PPC baseado só na formação específica. E não havia disciplinas nem por área, nem de formação geral. Porque, desde que a UNISC é UNISC, ela tem uma premissa, um compromisso com a formação integral. Ou seja, não é só habilitar profissionalmente, mas é preciso uma formação cidadã, que é crítica, reflexiva e humana.

\section{Entrevistadores:}

Entendemos perfeitamente. Mas também colocamos uma questão que, na nossa visão, sempre causou incômodo entre os professores do Departamento de Ciências Humanas: qual é a concepção de formação humanística que orientou essa discussão? E para nós, talvez precisemos fazer uma autocrítica, a concepção sempre passou pela presença e pela afirmação de algumas disciplinas, diretamente vinculadas ao Departamento.

\section{Carmen Lúcia de Lima Helfer:}

Eu sei.

\section{Entrevistadores:}

$E$ as nossas reclamações sempre foram pautadas pelo seguinte: "bem, eles estão tirando, estão reduzindo as nossas disciplinas"; portanto, estão comprometendo a ideia de uma formação humanística na Universidade. Talvez tenha faltado esforço e capacidade de um diálogo mais claro com as outras áreas de conhecimento e, inclusive, com a Reitoria.

\section{Carmen Lúcia de Lima Helfer:}

É uma noção boa, porque ela não está desatualizada, ela pode acontecer, porque o conhecimento da área da Filosofia, da Sociologia, da Antropologia, que são essas áreas que, tradicional e historicamente, fazem parte das Ciências Humanas, não vão sair do currículo. Elas não podem sair do currículo. Por quê? Porque elas são extremamente importantes para o cidadão, a pessoa e o profissional compreenderem a sociedade. Então, a pergunta é bem importante, porque em muitos cursos predominou a formação específica, com disciplinas específicas. E, inclusive, nós tínhamos problemas grandes, de terem disciplinas que num curso tinha um nome e num outro curso ela tinha outro nome, mas era o mesmo conteúdo. Quando eu saí da PROGRAD nós estávamos começando a fazer esse estudo, essa compatibilização para ver onde estavam as convergências e o que nós podíamos fazer para, então, ter uma formação mais integrada. E eu me lembro que houve uma discussão muito grande, onde as pessoas das Áreas específicas gostaram de lecionar, ou, então, desenvolver disciplinas onde eles mesmos pudessem dar Antropologia, Sociologia. E eu defendi que não, e eu defendo até hoje que não.

\section{Entrevistadores:}

Mas dai, professora Carmen, precisamos recolocar uma questão que você já respondeu, nas reuniões que a Reitoria promoveu para apresentar e discutir o projeto de Reinvenção Pedagógica. Há o risco de estarmos diante de um projeto no qual, para algumas áreas,

Barbarói, Santa Cruz do Sul, n.59 - número especial, p.<84-112>, Ago./Set. 2021 


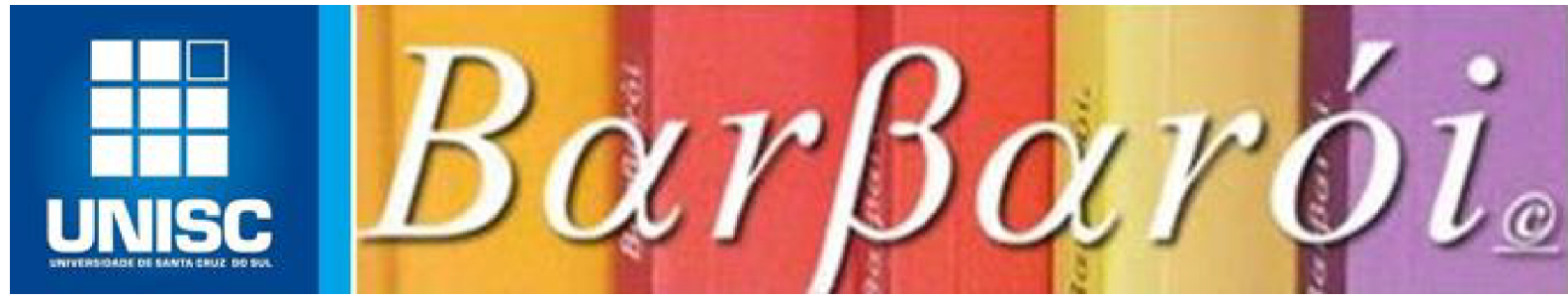

professores que não necessariamente têm formação poderão trabalhar? Por exemplo, professores que não têm formação em sociologia, antropologia, filosofia, mas que poderão trabalhar temas e objetos que estão vinculados às tradições de reflexão desses campos disciplinares?

\section{Carmen Lúcia de Lima Helfer:}

Eu confesso que entendo que isso não pode acontecer. Eu disse isso para colegas de vocês, eu disse isso publicamente e esse não é o projeto. Quando se traça, digamos, espaços curriculares interdisciplinares, estará aí o nosso grande desafio. É trazer a contribuição dos diferentes campos do conhecimento para o entendimento do conteúdo e da produção do conhecimento sob os múltiplos olhares. Daí porque a problematização, daí porque discutir problemas reais. E eu fiquei mais tranquila quando vi, percebi que, na formação geral, está resguardada a formação humana. O que é campo das Humanidades, da Filosofia, da Sociologia. E a pergunta que vocês fazem a vocês mesmos, nós não nos perguntamos. Talvez seja importante nesse novo momento de o departamento perguntar: como a saúde vê a aprendizagem? Ou, se não for para professor, que seja para os estudantes. O estudante tem que precisar que é importante. Mas nós temos que fazer ele entender que é importante. Agora, o modo como se faz isso pode ser diferente. E aí que mora uma esperança, de que através de problemas reais, através de uma compreensão da sociedade tal como ela é, você possa trazer os pensamentos de filósofos, sociólogos, antropólogos para elucidar essa sociedade.

É uma questão de metodologia? É. Mas é uma questão, também, de preservar campos do conhecimento. Em nenhum momento, pelo menos este Gabinete, teve a intenção de tirar esse campo da formação, de jeito nenhum. Porque no projeto político-institucional, quando se fala numa formação integral, você quer a formação de uma pessoa, de um sujeito que pensa. Um sujeito que pensa, não só a partir da sua área específica. Um engenheiro não vai pensar só Engenharia, ele tem que pensar o meio ambiente, ele tem que pensar o contexto social, porque ele vai atuar nele, e ele tem que entender isso. Então, penso que, mais do que nunca, e aí já vou responder uma das questões, nós estamos num tempo muito complicado. Talvez um dos mais emblemáticos da humanidade, porque é o mundo que está numa outra era, num outro momento. A tecnologia é implacável, ela não vai retornar, ela não vai diminuir. Ela vai avançar. Como nós podemos fazer que não nos tornemos robôs? Que não nos tornemos automatizados? A única forma de a gente fazer isso é fazer a reflexão da nossa humanidade, do nosso pensamento.

Então, penso assim, que cada vez mais nós vamos ter que trabalhar a formação humana e, talvez, ter que achar um outro modo. Se esse não for, como nós vamos fazer para que haja a compreensão dessa área e a relevância dela na formação das pessoas? A mudança é necessária.

Vamos aos departamentos. A Universidade de Santa Cruz do Sul, acho que era uma das únicas que mantinha departamentos, tirando as públicas. Nós nos criamos à luz e semelhança das universidades públicas. Só que as universidades públicas, de alguma forma, bem ou mal, são protagonistas do governo, do Ministério da Educação. Eu sempre digo, as nossas públicas

Barbarói, Santa Cruz do Sul, n.59 - número especial, p.<84-112>, Ago./Set. 2021 


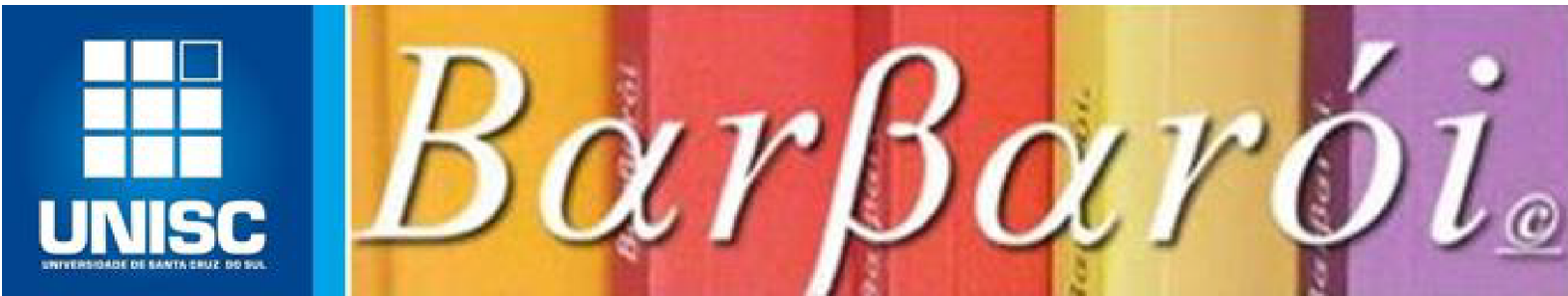

construir uma área. O que é uma área? É um campo maior. E que disso nasçam novos produtos. Sejam cursos, pós-graduação, extensão, serviços, que nós tenhamos, pelo conjunto, um fortalecimento maior das atividades, que possamos oferecer em torno da formação. Eu falei num discurso de formatura que a UNISC fez grandes reestruturações, temos o desafio de praticá-las, mas não mudamos nossa essência. A UNISC continua sendo uma Universidade comunitária, comprometida com a sua comunidade, com os princípios democráticos. Vem novamente a importância do Departamento de Ciências Humanas. Historicamente, o Departamento de Ciências Humanas fez um trabalho de reflexão democrática, dos modelos políticos. Foi muito importante e será sempre importante esse olhar da compreensão da política.

O Departamento de Ciências Humanas sempre teve importância. Nós tivemos reitores, nós tivemos pró-reitores, nós tivemos coordenadores, nós tivemos professores que sempre participaram de comissões importantes que envolviam decisões na Universidade. Então, desde lá nos anos 80, quando começou o movimento de democracia para dentro da Universidade, o departamento de vocês foi protagonista. E ele continua sendo. Mas com o crescimento da Universidade, criaram-se outras vozes. E o que é uma universidade se não uma universalidade de pensamentos? E a gente entende que o papel das Humanidades vai continuar. Eu entendo que o Departamento de Ciências Humanas, além da produção, outra questão importantíssima na história da Universidade, foi um departamento que sempre teve muita titulação, doutores. Mestres e doutores foram os primeiros a encampar essa batalha da titulação. E, com isso, também, contribuiu para a criação dos cursos de pós-graduação. Tanto que participam de praticamente todos os Programas Stricto Sensu. Participam da Saúde, do Desenvolvimento Regional que foi o primeiro, Direito, Letras, Educação e Psicologia.

Talvez vocês não tenham participação na Administração, no Sistemas e Processos Industriais. Vamos dizer que em 50\% dos mestrados e doutorados da UNISC temos professores das Humanidades presentes. Mas, o que é importante destacar: foram pioneiros. Sempre foram vanguardas nessa questão. E o Desenvolvimento Regional está aí para evidenciar, porque foi o primeiro mestrado interdisciplinar do Brasil, e foi capitaneado pelo Prof. Luiz Augusto e pela Prof. ${ }^{a}$ Virgínia. Hoje estão no mesmo departamento. Outra contribuição são as lideranças internas e externas, lideranças no campo da pesquisa, profissionais muito qualificados, com boa produção. Penso que essa foi a grande contribuição do Departamento.

\section{Entrevistadores:}

No entanto, fica uma lacuna nessa história. Que não é da UNISC, mas de muitas Universidades. Observa-se uma dificuldade persistente na consolidação de cursos da área das humanidades, em especial os cursos de Filosofia e de Ciências Sociais. E é claro, a pergunta é se estamos fadados a uma história sem a presença desses cursos ou se é possivel construir estratégias para que isso não ocorra.

\section{Carmen Lúcia de Lima Helfer:}

Barbarói, Santa Cruz do Sul, n.59 - número especial, p.<84-112>, Ago./Set. 2021 


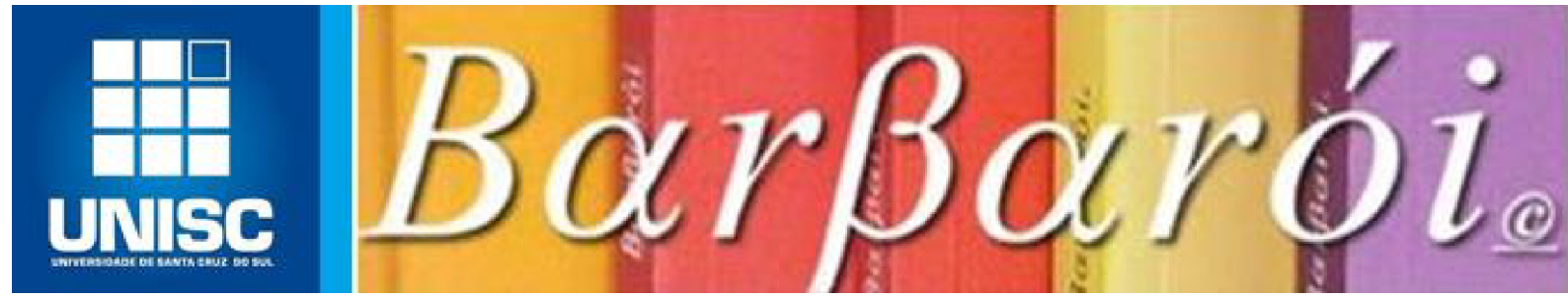

Essa é uma questão importante. Eu não vou ter essa resposta, eu só quero dizer que é comum a pergunta. Nós ainda mantemos na UNISC dez licenciaturas. Nós somos a única comunitária que temos esse número. A ferro e fogo, nós vamos achando formas de mantê-las, seja na integração de currículos, seja na junção de docentes, enfim, 'n' formas, e eu acho isso muito bacana, de todos os gestores que tivemos de manter o compromisso social, com a formação de professores, com as Humanidades, com a educação. Agora, até quando? Nós criamos o curso de Ciências Sociais, não vingou. Ou vingou enquanto deu conta de um conjunto de interessados. Porque tem uma outra coisa que paira sobre a nossa sociedade, entre o custo, o investimento e o depois, o futuro. E, infelizmente, juntou com uma fase muito ruim do Estado do RS, que foi a falta de abertura de concursos públicos, a não contratação. O que nós tivemos nesse meio tempo foi a inserção de Filosofia e Sociologia nos currículos do ensino médio. Agora eu nem sei como está, porque as áreas mudaram. Então, eu penso que isso não foi construído internamente. Houve uma intenção interna de ofertar, mas houve um externo que não favoreceu e não teve procura. Eu me lembro que quando eu estava na PROGRAD, a gente encerrou o curso de Filosofia. Porque não tínhamos alunos.

Nós tínhamos que construir disciplinas, inserir os alunos em disciplinas existentes. Foi muito difícil, até que chega um ponto que não tem como manter. Aí, o que aconteceu? Aconteceu que essas áreas foram mantidas nos cursos. Em 2020, uma outra mudança vai ocorrer. Vamos fazer todo um esforço e vocês estão absolutamente dentro para que a gente resgate cada vez mais esse valor. Eu vi que os professores da formação geral, muitos são das Humanidades. Gostei do que vi. E não sai, de jeito nenhum, dessa Instituição a importância de formar pessoas, e cada vez mais pessoas mais inteiras. Nós vamos ter nesse mundo mais depressão, mais suicídios, mais um monte de coisas. Nós estamos vivendo um momento muito difícil porque um percentual ainda muito grande de egressos da graduação estão sem emprego.

As pesquisas indicam que o momento é de desemprego, mesmo entre pessoas que têm curso superior. Então, vamos pensar numa família no Rio Grande do Sul, com o salário dos professores, com pagamento parcelado em míseras parcelas. Como incentivar seus filhos a entrarem em cursos comprometidos com a formação de professores?

\section{Entrevistadores:}

Mesmo para jovens que têm interesses em outras áreas. Como enfrentar no cotidiano de sala de aula, da formação universitária, justificar para os estudantes que os cinco anos de graduação darão para eles condições de inserção no mercado de trabalho, quando essa promessa, pelo menos na nossa conjuntura, está distante de ser alcançada. É uma promessa que tem grande chance de não ser consequente.

\section{Carmen Lúcia de Lima Helfer:}

Não vai ser cumprida porque quando ele é um estagiário, enquanto graduando, terá um salário. Se ele terminar a graduação vai ganhar menos do que um estagiário. Então, assim, as condições estão muito ruins. E eu fico triste com a situação para esses jovens que se formam, felizes da vida, eu fico pensando "meu Deus, daqui a uns dois ou três meses vai cair a ficha".

Barbarói, Santa Cruz do Sul, n.59 - número especial, p.<84-112>, Ago./Set. 2021 
